\title{
Slope movements in a dynamic environment - A case study of Tachia River, Central Taiwan
}

\author{
Jiun-Chuan Lin ${ }^{\mathrm{a}, *}$, David Petley ${ }^{\mathrm{b}}$, Chia-Hung Jen ${ }^{\mathrm{a}}$, Alexander Koh ${ }^{\mathrm{c}}$, Mei-Ling $\mathrm{Hsu}^{\mathrm{a}}$ \\ ${ }^{a}$ Department of Geography, National Taiwan University, No. 1 Sec. 4, Roosevelt Rd., Taipei 106, Taiwan \\ ${ }^{\mathrm{b}}$ Department of Geography, University of Durham, Durham DH1 3LE, UK \\ ${ }^{\mathrm{c}}$ Department of Remote Sensing and GIS, Bath Spa University College, Newton Park, Newton St Loe, BA2 9BN, UK
}

Available online 28 November 2005

\begin{abstract}
It is well established that landslides are extensively triggered as a result of large seismic events in upland areas. Some authors have postulated that sediment moves through the drainage system as a 'slug', whilst others have noticed only limited impact as material remains stored in the drainage basin. What has almost never been addressed is the continued evolution of the landslides themselves after the seismic event, and their continued role in releasing slope materials. This paper examines the Tachia River basin in western Taiwan, which was extensively affected by landslides during the 1999 Chi-Chi earthquake. Using vertical cartographic aerial photographs and satellite images, this study demonstrates that the area affected by landslides increased substantially after the main earthquake as a result of high intensity rainfall events. Analysis of suspended sediment data from downstream of the area affected by landslides, show that sediment concentration steadily increases with time, in the period after the initialization of slope movements. A model in which sediment production increases immediately after the earthquake and then steadily reduces through time appears to be over simplistic, and should be replaced by a model that incorporates complex responses to the initial and subsequent events.
\end{abstract}

(C) 2005 Elsevier Ltd and INQUA. All rights reserved.

\section{Introduction}

Landslides are an important part of the natural landscape system in dynamic mountain environments that experiences constant uplift. These slope failures serve as efficient mechanisms for detaching and mobilizing slope-forming materials into the fluvial system, for eventual removal by channel flow processes. Most landslides require a triggering event to initiate movement. In many cases this is a high intensity and/or long duration rainfall event, and there are numerous well-documented examples of extensive landsliding during, for example, monsoon rainfalls or the passage of tropical cyclones (Central Weather Bureau, 2004). The other main trigger for landsliding is the occurrence of a large seismic event (Keefer, 1984). The shaking associated with big earthquakes triggers extensive landsliding, sometimes at distances of more than $100 \mathrm{~km}$ from the epicenter. The release of sediments into the fluvial system may be highly

\footnotetext{
*Corresponding author. Tel.: + 886223687056 ; fax: + 886223687056 .

E-mail address: jclin@ntu.edu.tw (J.-C. Lin).
}

episodic, with large rainfall or seismic events causing the release from the slope of sediment, which is then removed by subsequent large flow events of the associated river system, possibly in the form of 'sediment slugs'.

Dynamic environments often experience simultaneous combinations of uplift, seismic events, and high precipitation within very short time intervals, and the interactions in terms of space and time between these events must be considered. In simple terms, perhaps the most dramatic event to which such a landscape can be subjected to, is the occurrence of a large earthquake during the passage of a tropical cyclone. At present, it is difficult to characterize the landscapes that would result from such events. These combined events may be regarded as "formative events" for these environments. The hypothesis that, "large earthquakes detach slope forming materials, and subsequent rainfall events transport these into the fluvial system, to increase the likelihood and efficiency of sediment movement by subsequent hydrological events", is proposed, and to date such postulations, though logical, have been essentially conjectural. 
This study investigated the coupling between the occurrences of landslides triggered by high-magnitude rainfall events, associated with the passage of typhoons, and the occurrence of a large seismic event, of a magnitude 7.6 earthquake. The study is centered on a catchment in the Central Mountains of Taiwan, a region that underwent extensive landsliding during the Chi-Chi earthquake of 1999 (Murphy et al., 2002; Dadson et al., 2003, 2004). The results show that the occurrence of landslides during the typhoons is radically increased as a result of the earthquake, and that the pattern of mobilization of sediments into the fluvial system is also greatly altered.

\section{Dynamic environment of Taiwan}

The island of Taiwan is located on the boundary between the actively colliding Philippine Sea and Eurasian Plates. The collision occurs as a result of the west-north-west movement of the Philippine Sea Plate, with a net movement rate of about $7 \mathrm{~cm} \mathrm{yr}^{-1}$. In Taiwan, the area of collision between the plates is atypical, and involves an essentially conservative mountain-building event. In consequence, Taiwan experiences relatively high uplift rates, though actual measurements of these rates vary somewhat. For example, Peng et al. (1977) measured rates of c. $2 \mathrm{~mm} \mathrm{yr}^{-1}$ for the period $1500-5500$ years BP for northern Taiwan, whilst Konishi et al. (1968) estimated rates of $1.8-4.8 \mathrm{~mm} \mathrm{yr}^{-1}$ in the Central Range varying from north to south. The consequence of these high uplift rates has been the formation of a large mountain chain extending in a north-south direction throughout central Taiwan, which is characterized by steep slopes, a weak and comparatively young rock mass, and the presence of numerous large structural lineaments. The maximum elevation of the mountain chain is $3952 \mathrm{~m}$, and more than 200 peaks exceed $3000 \mathrm{~m}$ ASL.

The climate of Taiwan ranges from tropical to subtropical, with high maximum daily temperatures in the summer months of June to September. Precipitation is high, and is often dominated by tropical cyclones (typhoons) during the months of June-November. On an average, 3.8 typhoons affect Taiwan per annum, with rainfalls regularly exceeding $500 \mathrm{~mm}$ during the $48-72 \mathrm{~h}$ passage of these violent weather systems. A direct hit by a large typhoon combined with the orographic effects of the steep mountain chains, produce very high precipitation totals and intensities. For example, recorded $24 \mathrm{~h}$ precipitation for Typhoon Herb (1996) was $1748.9 \mathrm{~mm}$ at Alishan located in the middle section of the Central Mountain range, with peak $60 \mathrm{~min}$ intensities exceeding $100 \mathrm{~mm} \mathrm{~h}^{-1}$. These are usually followed by major natural hazard events that often result in extensive damage and destruction, and considerable loss of life.

The seismicity of Taiwan is well documented even though the complexity of the tectonic setting is not fully understood. The island experiences comparatively frequent large earthquakes, the most notable recent event being the
Chi-Chi earthquake of 1999. On 22nd September 1999, at $0147 \mathrm{H}$ local time, an $86 \mathrm{~km}$ long rupture of the Chelongpu Fault, a north-south orientated, eastward dipping thrust fault on the western side of the Central Mountains induced an earthquake of magnitude $M_{\mathrm{L}}=7.4$. This event resulted in 2405 fatalities and led to an estimated direct and indirect economic loss of US\$30 billion. The Tachia River valley study site is located approximately $30 \mathrm{~km}$ from the earthquake rupture, and suffered extensive, well-documented damage as a result of the earthquake shaking (Soil and Water Bureau, 2000).

\section{Study site}

The study site is located in the center of the Tachia River valley in central western Taiwan (Fig. 1). This river valley is notable because it incorporates the Central Cross Island Highway that links the east and west coasts of Taiwan across the Central Mountains. This very important infrastructure was constructed in the early 1960 s, and was followed by a series of economically significant hydroelectric schemes that extend along the length of the river, consisting of one high, concrete arch dam at Techi, and a series of "run-of-the-river" schemes along the watercourse. The study focused on a $5 \mathrm{~km}$ straight line distance, stretch of the river between the $41 \mathrm{~km}$ mark of Highway 8 in the west and the high dam at Techi in the east (Fig. 2). This area of interest suffered extensive damage, and to date, five years after the event, it has not yet been possible to reopen the road.

The area consists of a steeply incised valley orientated approximately east-west in the eastern part of the Central Range. The geology consists of a series of interbedded Tertiary sandstones and slates, with occasional limestone bands. The rock mass is extensively tectonically disrupted, with a high density of fractures and joints. Slope angles are in the range of $40^{\circ}-80^{\circ}$ and the elevation of the highest peaks in this area extends to approximately $3250 \mathrm{~m}$ (Fig. 3).

For this area SPOT IV multi-spectral satellite imagery, acquired April 1999 and January 2000 (Fig. 4), vertical 1:17500 scale cartographic aerial photography for June 2001 and July 2004 (Fig. 5), and 1:25000 scale topographic maps, revised in 1986 to include the existing large landslides (Fig. 6), are available. These have been image processed and geo-rectified to determine the rate of landslide activity before, during and after the earthquake.

Rainfall data for the area of interest has been collated for the period July 1981-July 2002. These show that maximum rainfalls occur during the months of July-September (Fig. 7).

These observations are then related to the rates of suspended sediment movement in the main channel as measured at three gauging stations, one located upstream of the area affected by landslides at Sung-Mao, the other immediately downstream at Dong-Mau Chi and Pai-Lu Bridge (Figs. 2 and 8). 


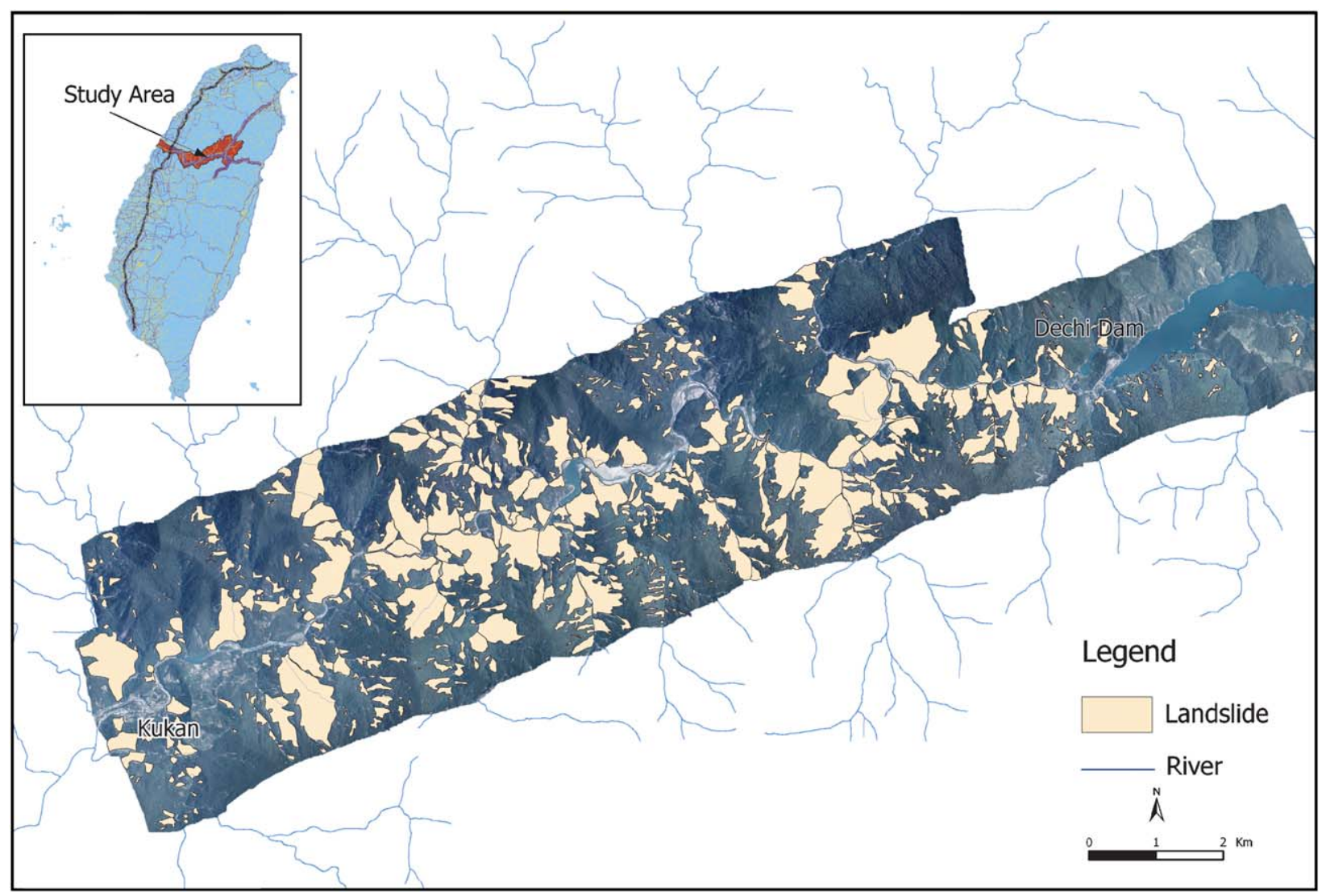

Fig. 1. Location map of study site, showing the major highway network and the 531 landslides mapped in June 2000 within the river catchment.

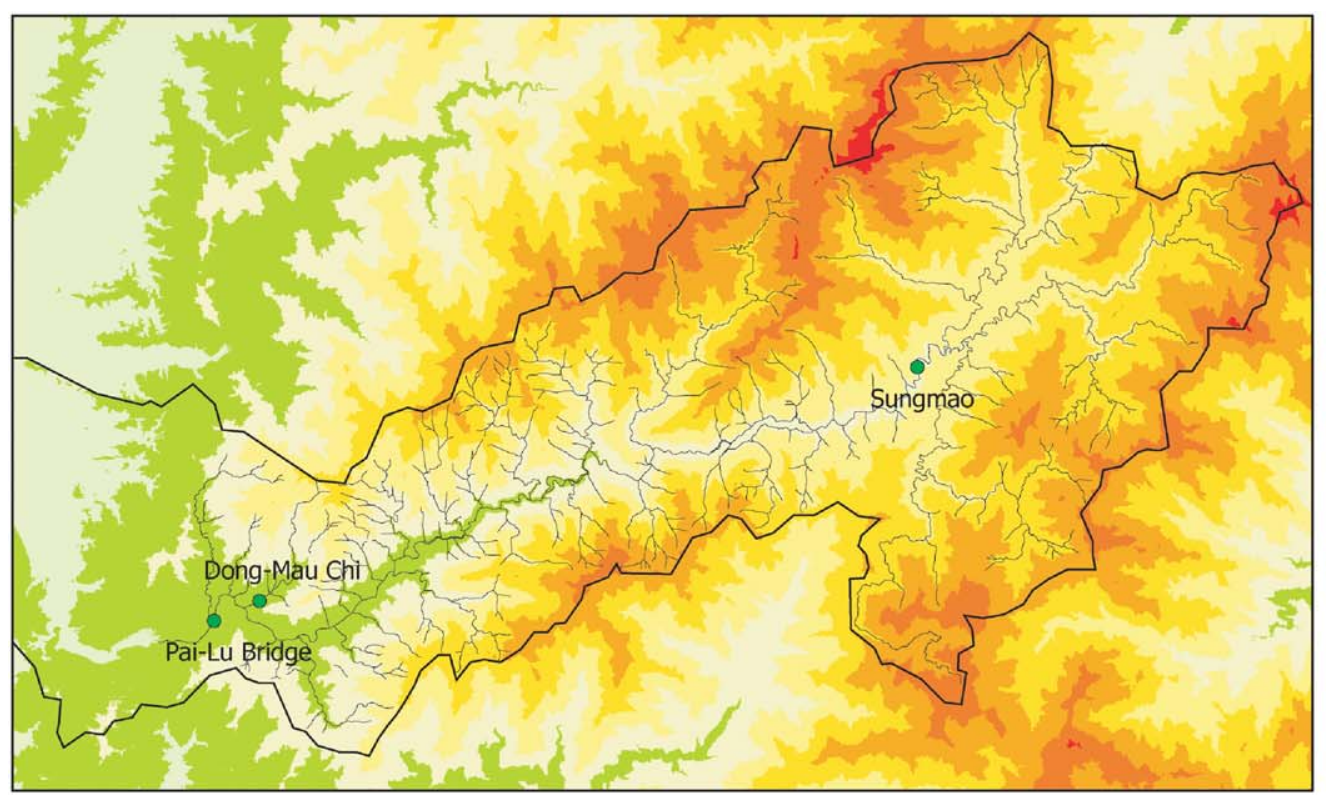

\section{Legend}

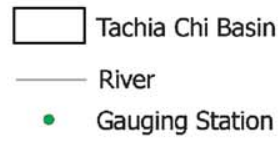

Fig. 2. The extent of the Tachia Chi Basin and locations of gauging stations.

\section{Results}

\subsection{Landslides and sediment concentrations in the study area prior to the 1999 earthquake}

Image interpretation in parallel with change analysis of SPOT and aerial photography data, used in combination with the topographic maps, demonstrate that prior to 1999 , four landslides are clearly identifiable. Three of these were located directly below the road on the south side of the Tachia River. The SPOT image suffered from shadow effects on the south side of the river valley, and as a result, any landslides within this area cannot be reliably mapped. The SPOT image confirmed the presence and area extent of 

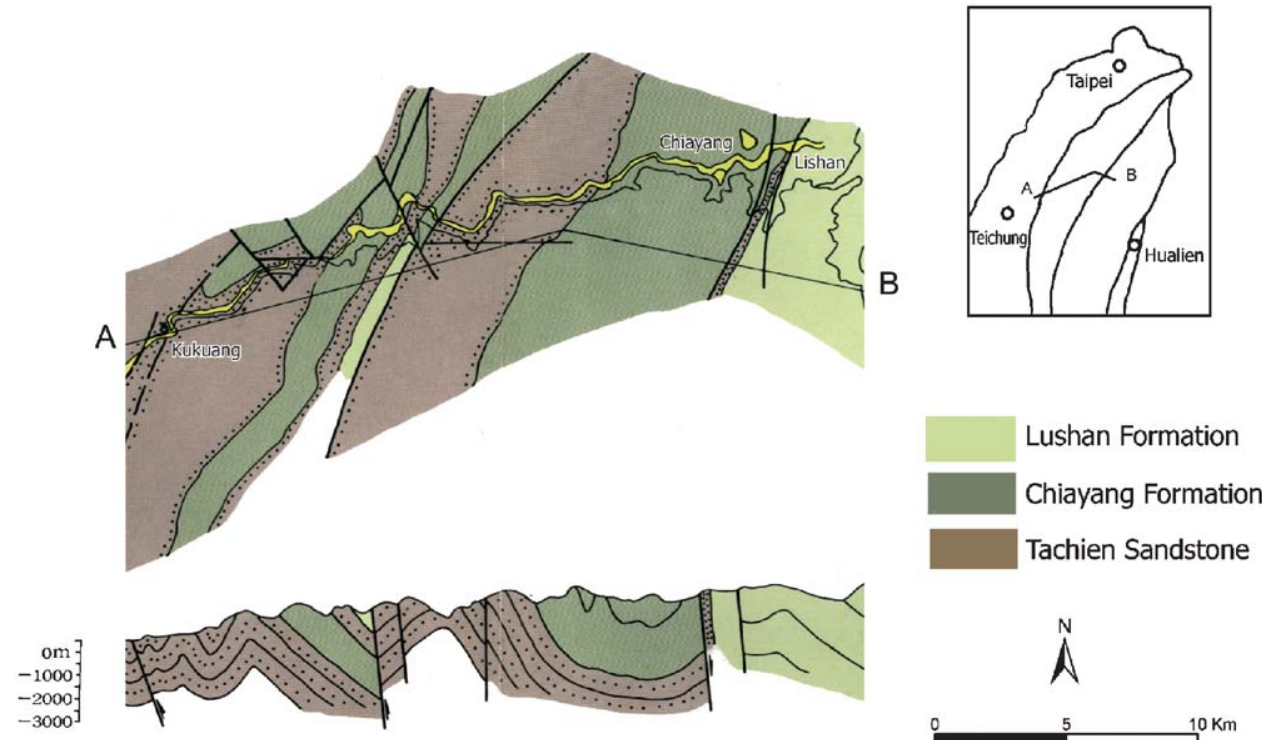

Fig. 3. Geological map of study area.
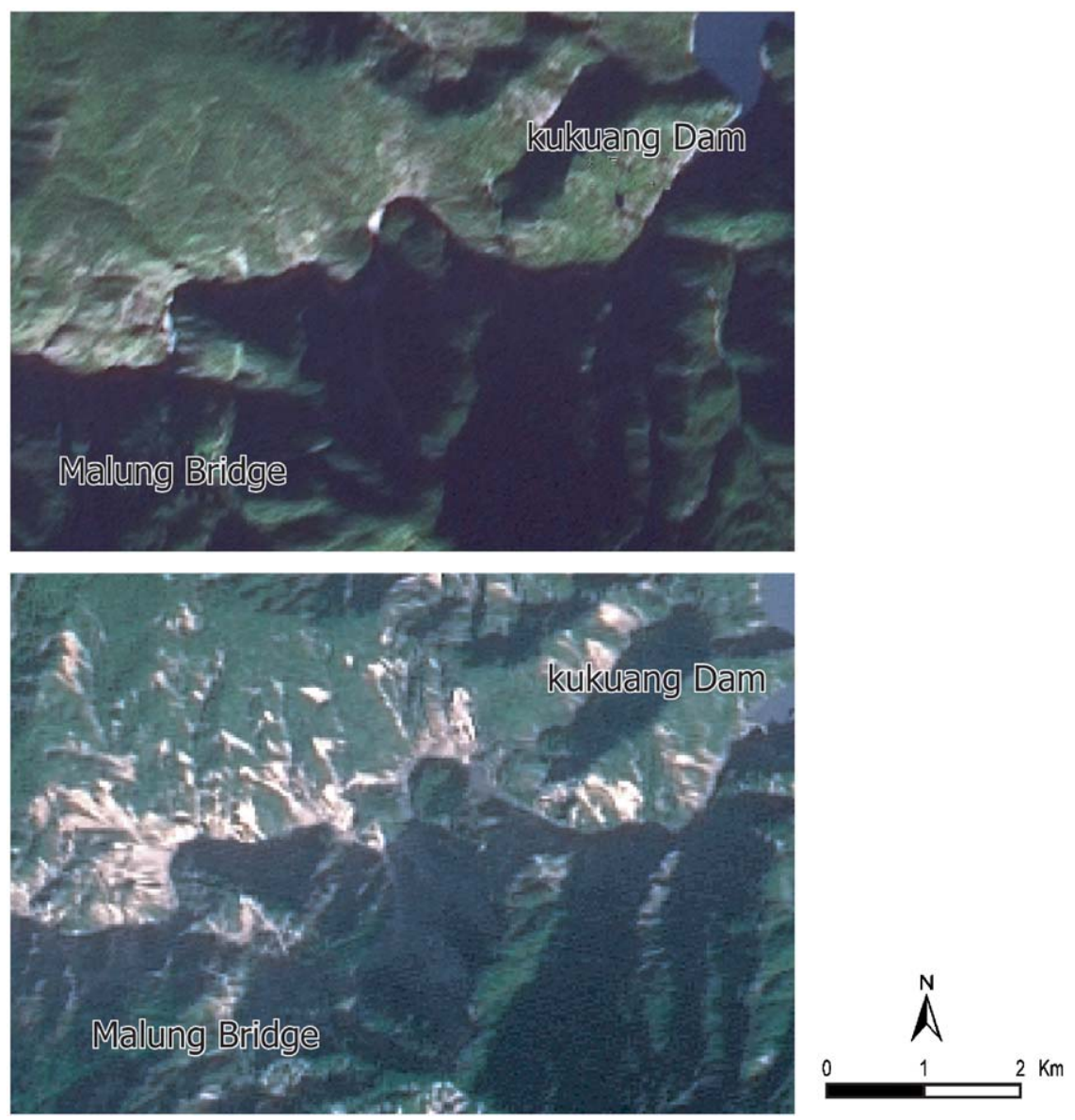

Fig. 4. SPOT IV image, April 1999 (top) and January 2000 (bottom), of the study area before and after the earthquake event, showing the significant increase in slope failures after the Chi-Chi event.

the landslides on the northern side of the river, and draws attention to a number of other large landslides on the north side of the river, especially on the western margin of the study area. Most of the remaining areas are densely forested, and these areas may be associated with higher levels of stability. Although the SPOT IV image was collected some months before the earthquake, and precipitation was exceptionally low in 1999 , it is reasonable to 


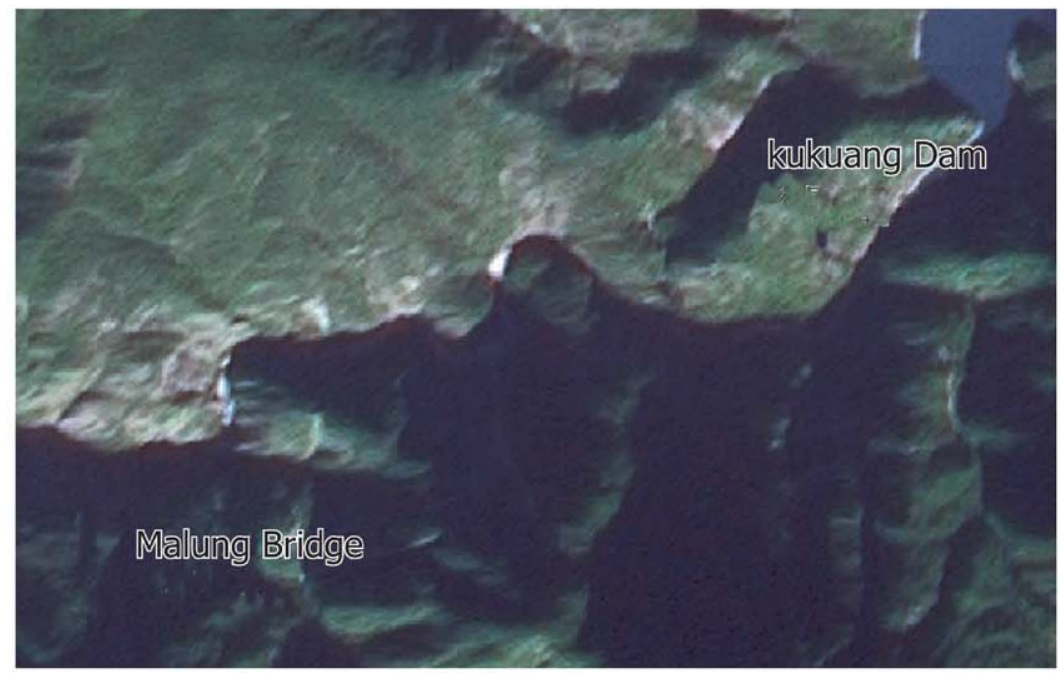

\section{4/1999 SPOT}
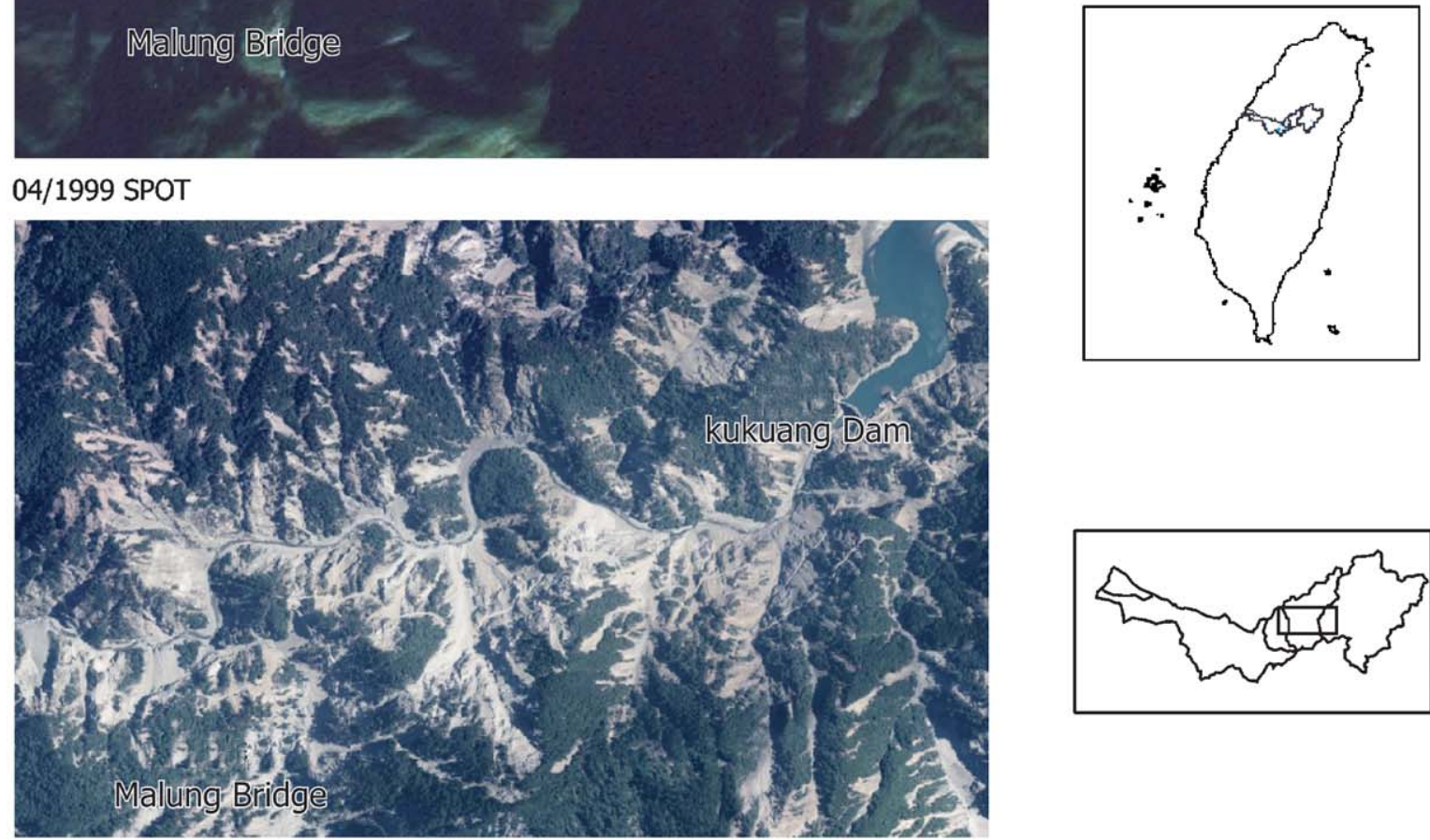

\section{6/2001 Aerial Photo}
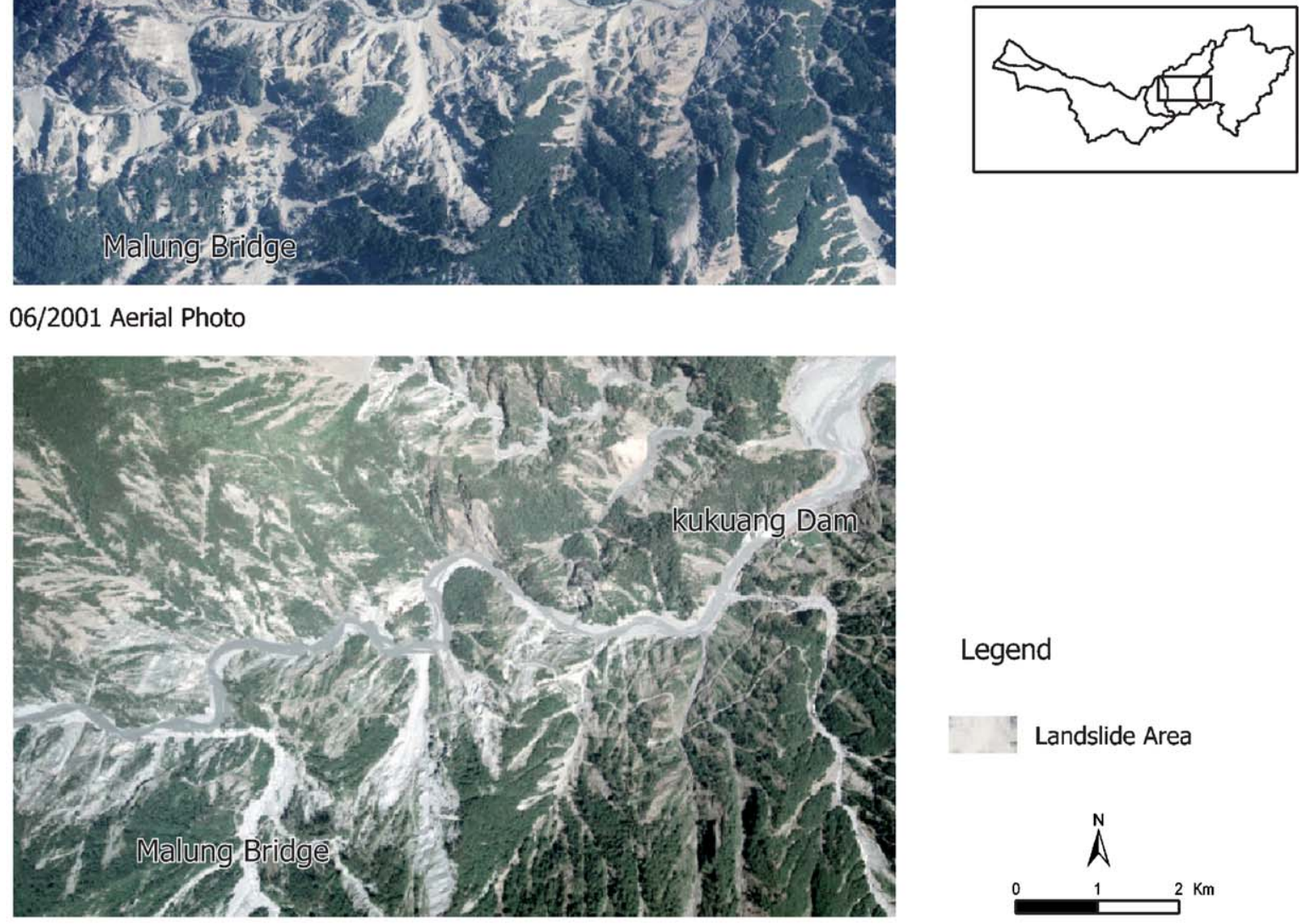

07/2004 Aerial Photo

Legend

Landslide Area

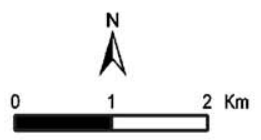

Fig. 5. September 1999 (top), June 2001 (middle) and July 2004 (bottom), aerial photography of the area of interest. 


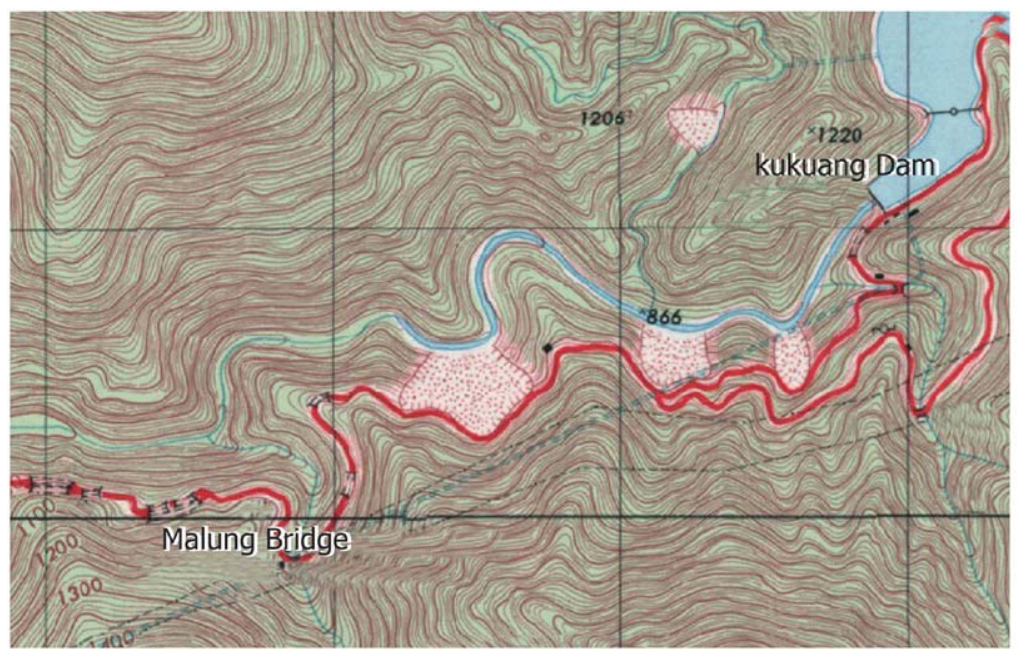

Legend

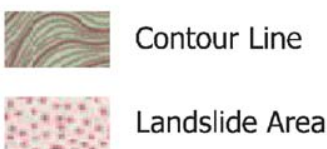

Reservoir

Central Cross Island Highway

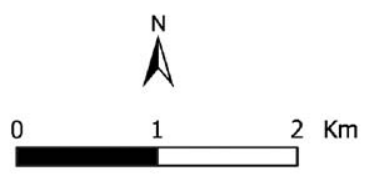

Fig. 6. Contour map of Kukuan Dam area, which shows four large landslides on the May 1986, 1:25000 scale map.

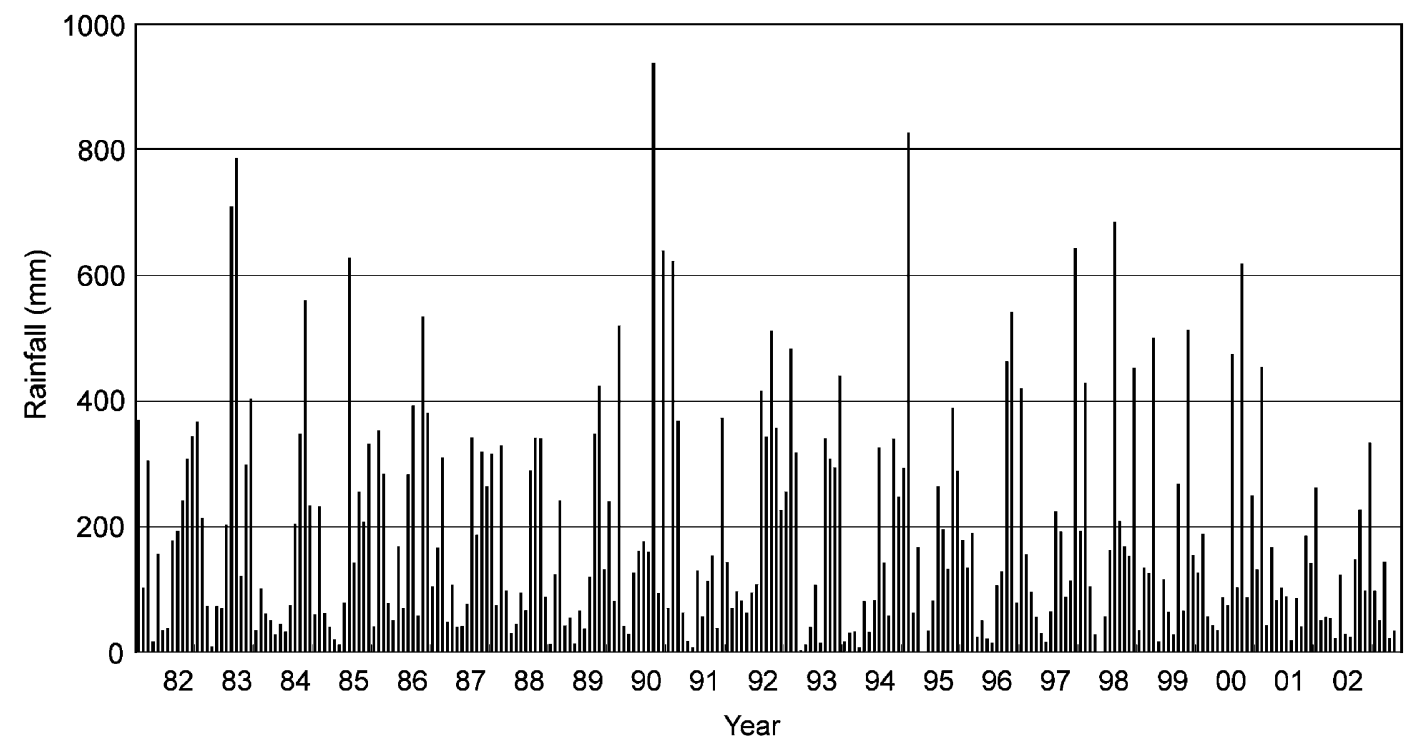

Fig. 7. Rainfall data for the period 1981-2002.

assume that the observed distribution of landslides is representative of the distribution at the time of the Chi-Chi event.

\subsection{Landslides and sediment concentrations in the study area post Chi-Chi earthquake}

Image interpretation in parallel with change analysis of SPOT and aerial photography data, conducted with reference to the topographic maps, demonstrate that post the Chi-Chi event, over 21000 landslides occurred throughout Taiwan (Soil and Water Bureau, 2002), including 650 slope movements along the Tachia River Valley between Techi and Kukuan. The SPOT IV image acquired within the dry season in Taiwan, shows that along this section of the valley extensive landslides were triggered
(Fig. 3). Again, the image was obscured by shadow on the south side of the valley, although a number of new landslides can be identified. On the north side extensive new landslides are also evident. Close examination of the image shows that these are mostly translational rockslides/ rockfalls that have occurred on steep slopes. In common with the observations made by Dadson et al. (2004), it is clear that a large proportion of the slides were initiated from the ridge top, which is characteristic for earthquaketriggered landslides. The occurrence of so many landslides in this area is interesting as the density here is much higher than that seen in most parts of Taiwan. One possible explanation for this is the role of topographic amplification (Murphy et al., 2002; Sepulveda et al., 2004), in which an interaction between the slope height and the earthquake wave, controlled by the seismic wavelength, leads to a 

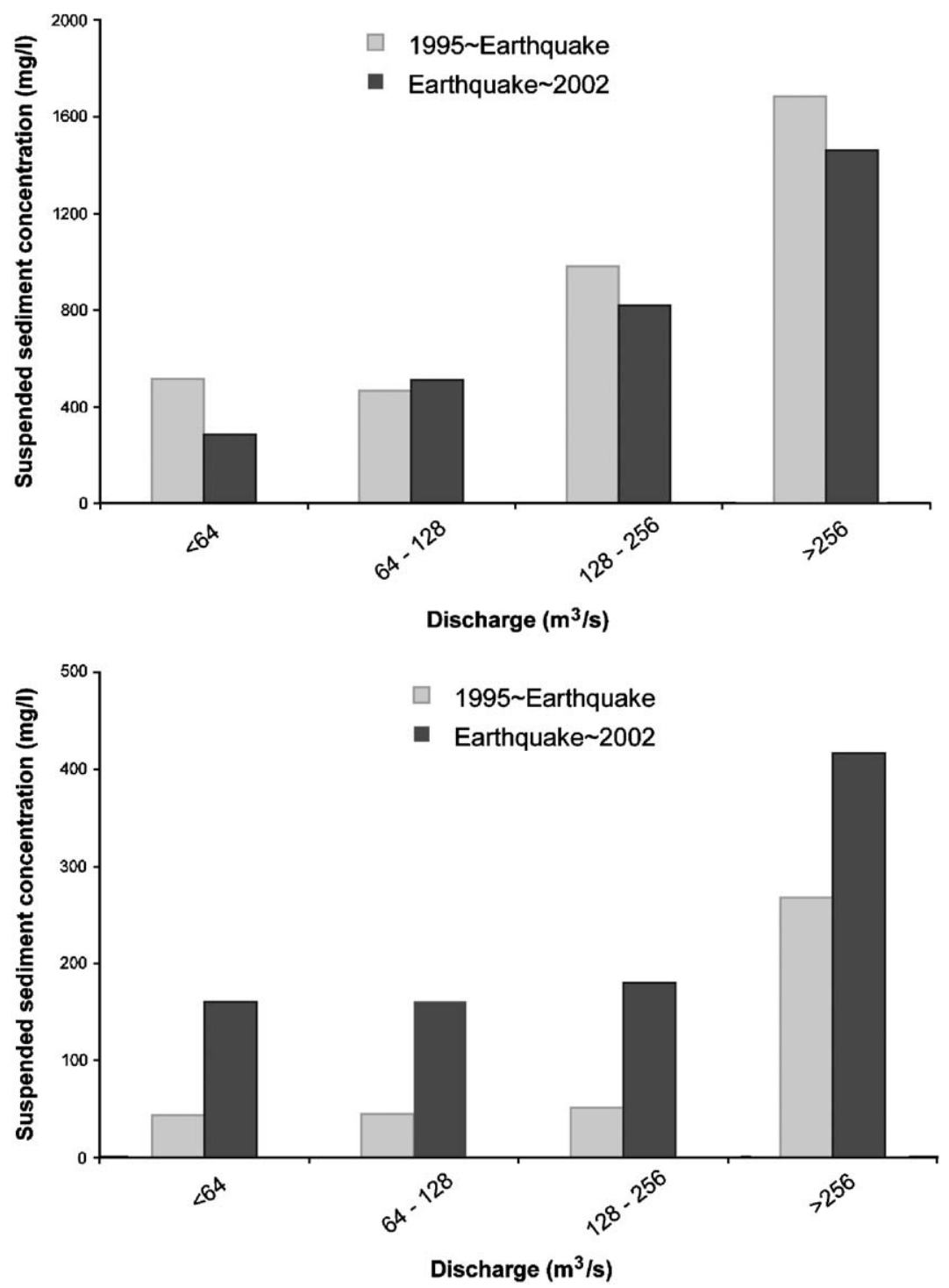

Fig. 8. Suspended sediment concentration pre and post Chi-Chi earthquake for (upper) Pai-Lu Bridge and (lower) Sung-Mao.

resonance effect on the slope that increases peak ground accelerations and hence trigger landslides.

This high density of landslides is confirmed by highresolution vertical aerial photography acquired in July 2000 , before any substantial amounts of rainfall had affected the study area (Fig. 4). Whilst at first glance the aerial images appear to show a higher density of landslides than is evident from the SPOT IV image of January 2000, close examination shows that this is primarily the result of the difference in the resolving capabilities of the remote sensing data. Examination of individual landslides has shown that their distribution and morphologies are essentially unaltered.

The area experienced two intense rainfall events in year 2000 as a result of the passage of typhoons across the study area. On 21-23 August 2000, Typhoon Bilis deposited $269 \mathrm{~mm}$ of rainfall at Alishan over a period of 2 days, and on 29-30 July 2001, Typhoon Toraji deposited $365 \mathrm{~mm}$ of rainfall over the same area in 2 days. Three other large rainfall events followed and these delivered in excess of $200 \mathrm{~mm}$ of rainfall during 2001. Since then, at the time of writing, a further four typhoons have affected this area. The effects of these large precipitation events can be seen on the aerial photographs (Fig. 9).

The landslides have developed considerably during these rainfall events, primarily through retrogression to form wider scarps and through lateral extension. In many cases the down slope debris tracks have been widened (Fig. 9), and many new landslides have developed, probably as a result of the weakening of the slope materials by the earthquake. This greatly increases their vulnerability to failures during subsequent rainfall events.

The widely reported extensive landsliding triggered by the Chi-Chi earthquake probably does not represent the peak intensity of landslide activity resulting from this event. It is evident that since the earthquake the occurrence 
$09 / 1999$

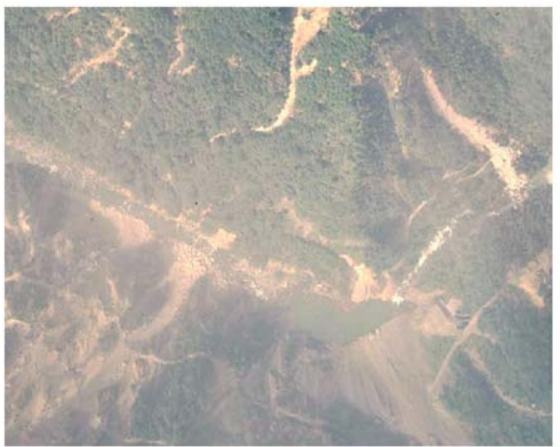

$08 / 2001$

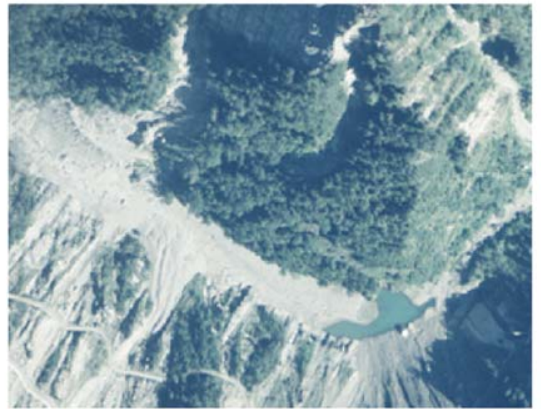

Fig. 9. Aerial photography showing increase in landsliding events after the Chi-Chi earthquake and Typhoon Bilis and Toraji.

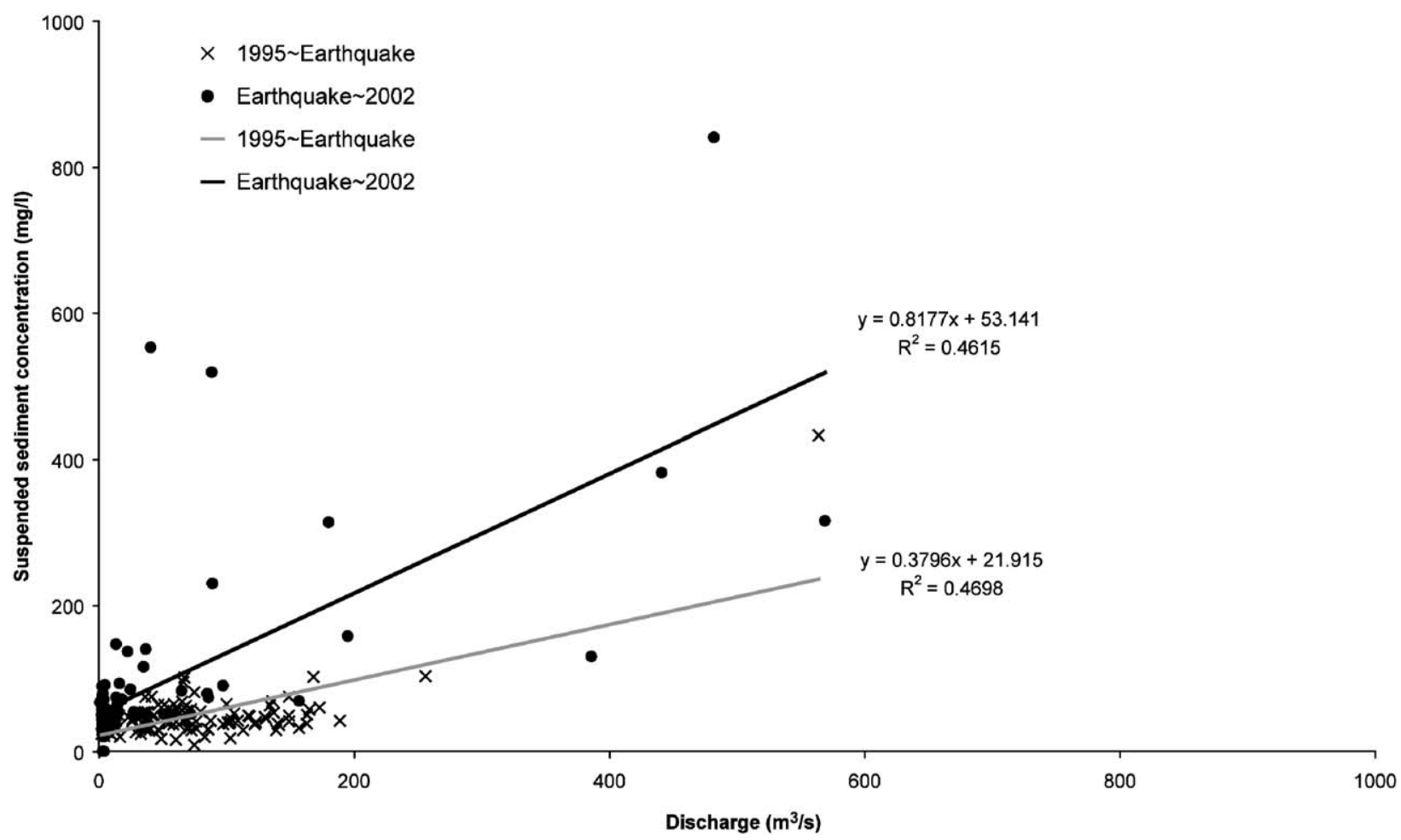

Fig. 10. Sediment concentration plot for Pai-Lu Bridge, pre and post Chi-Chi earthquake.

of landslides has increased as a result of typhoon activity, which has mobilized the debris and triggered a new set of landslides.

$06 / 2000$
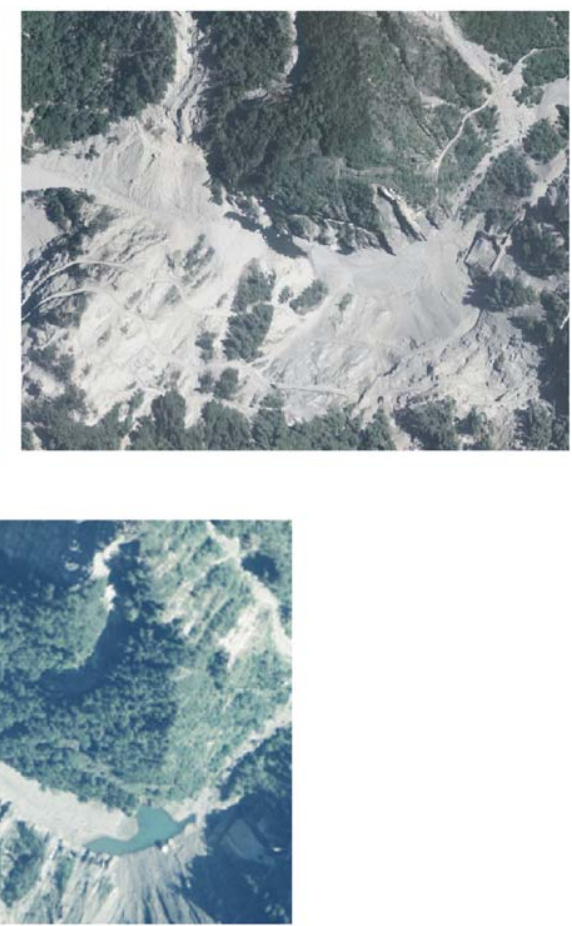

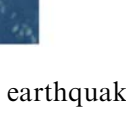


section, a gauging station is maintained at Pai-Lu Bridge, by the Hydraulic Bureau of Taiwan. This station holds discharge and suspended sediment data at 5-day intervals. The gauging station consists of a V-notch weir at which discharge and suspended sediment concentrations are measured.

Changes to the dynamics of the sediment delivery system can be analyzed by examining a plot of suspended sediment concentration collected before and after the earthquake. The data plot shows a change through time before and after the Chi-Chi event (Fig. 10). The graph suggests that there is no significant increase in sediment concentration at all flow rates before the Chi-Chi earthquake, and significant increases from, for example, $75-750 \mathrm{gl}^{-1}$ in sediment concentrations for flows of $100 \mathrm{~m}^{3} \mathrm{~s}^{-1}$. It is useful to note that the baseflow remains the same for pre and post Chi-Chi conditions, and it is suggested that this may be a result of channel management for ensuring continuous supply of water.

\section{Discussion}

Pearce and Watson (1986) noted that in seismically active mountainous regions, earthquake-triggered landslides probably represent the main regional sedimentsupply mechanism. However, they also suggested that the sediment thus released goes into channel stores before being progressively transported by the river out of its catchment. Thus, a model was proposed in which the earthquake liberates the sediment, but then there is a progressive response of the landscape in which the system effectively moves towards a more stable state as the products of the earthquake are removed. Keefer (1984) noted that the actual landslide is only the first stage of a series of processes in which sediment is removed from the slope, and will then be transported out of the catchment by fluvial processes. However, there has been a consensus in the literature that deals with the sediment released by earthquakes, as independent from that of other subaerial processes. Earthquakes are regarded as discrete entities in space and time, which spontaneously release sediment by triggering landslides. Subsequent weathering weakens the material and prepares it for the next event. These sediments migrate through the system with time and their effects diminish as the landscape "heals" through revegetation.

It is clear that after the earthquake the efficiency of the river in delivering sediment increases substantially (Fig. 11). This suggests that prior to the earthquake, in spite of the dynamic nature of the environment in Taiwan, the mode of sediment transportation of the Tachia River is sediment supply limited. The liberation of large volumes of sediment during the Chi-Chi event addressed this limitation by increasing the sediment supply, to the point that the river no longer works on the sediment supply limited mode.

In reality this is probably an overly simplistic view. First, the severity of the impact of the earthquake depends heavily on the state of the groundwater at the time as the subaerial system plays a key role in determining the efficiency of the seismic event in triggering landslides (Rodriguez et al., 1999). In the case of Chi-Chi, 1999 was an exceptionally dry year, thus groundwater levels were low. Under such conditions, the efficiency of the seismic

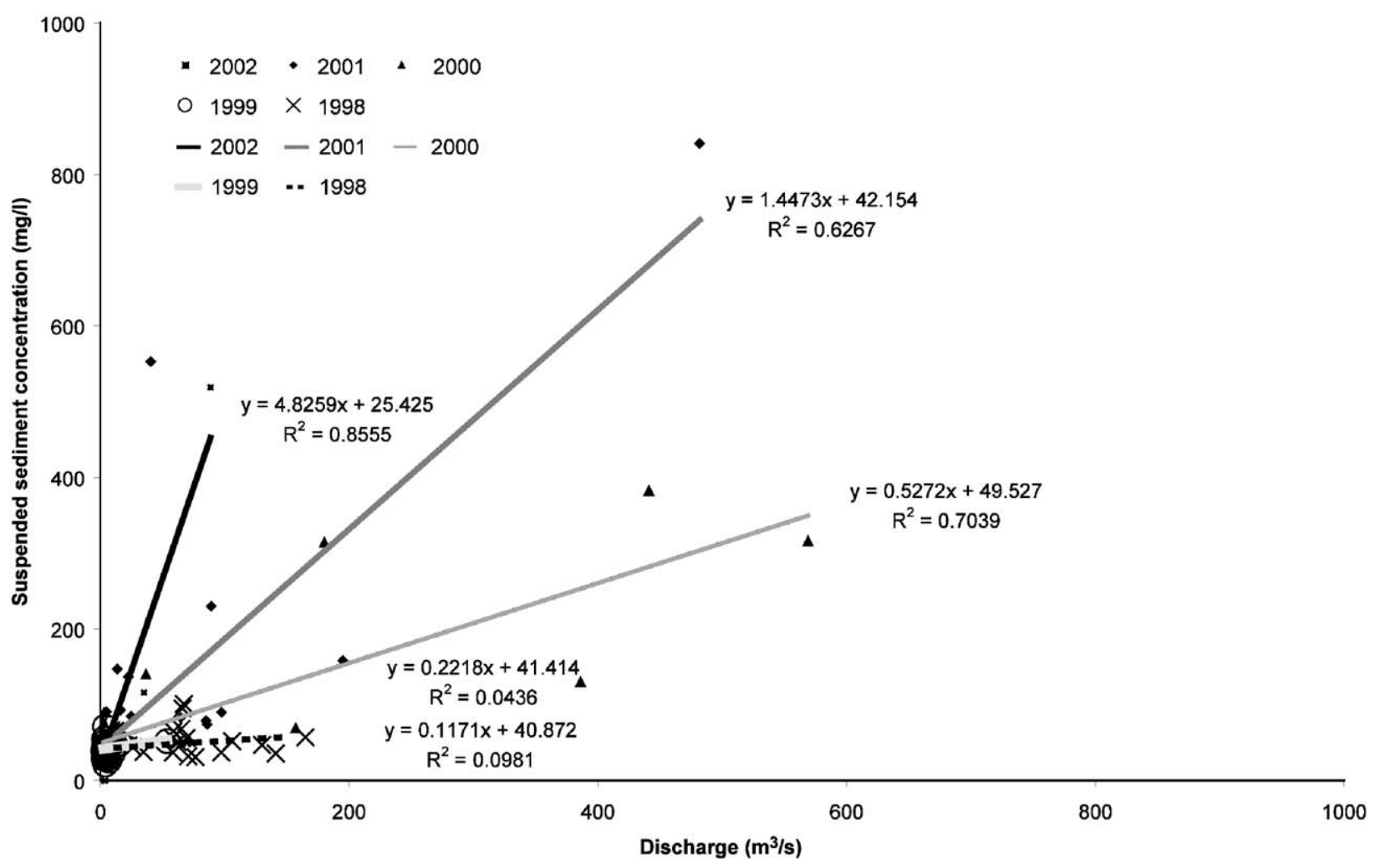

Fig. 11. Changes in sediment concentrations between 1998 and 2002. 
event in inducing landslides would be greatly restricted. Second, the earthquake should not be seen as a single event, but more as the combination of a series of interrelated events including after-shocks. In the case of the Chi-Chi earthquake, the aftershock sequence included six events of $M_{\mathrm{w}}=6.3$ or greater, all of which were large enough to trigger landslide activity by themselves.

The role of landslides in sediment delivery may be illustrated with reference to data from the Sung-Mao gauging station, located in the upper part of the Tachia River catchment. This area is located sufficiently far away from the earthquake rupture zone that extensive landslides did not occur. Sediment concentration measurements at this station are only undertaken during large events, so care is needed in the analysis of the data. The analysis of the available data reveals no significant change and, probably even a slight decrease in sediment concentration at this station after the earthquake (Fig. 7). Data of large events at the Pai-Lu Bridge station demonstrates significant increase in sediment concentration after the earthquake. This further emphasizes the importance of seismic events in changing the fluvial transportation regime by triggering numerous landslides, which subsequently introduces large amounts of sediment into the system.

It is clear that such a seismic sequence is an efficient mechanism for releasing sediment into the fluvial system (Keefer, 1984). However, it is also well established that in many cases the fluvial system may lack the required capacity to remove the sediment. The Taiwan data presented provides an interesting perspective. In this environment, landslides provide substantial amount of sediment ready for transportation by the powerful mountain streams during subsequent typhoons, and the area of earthquake-induced landslides also increases during typhoons. This may be attributed to shaking that loosens and weakens the sediments to the point that their slope stabilities are compromised during the subsequent intense rainfall events, and the resultant slope failures delivers significant volumes of sediment into the fluvial systems.

Dadson et al. (2004) examined sediment production data for the Chosui River to the south of the study area, and noted a decrease in mean sediment delivery from this river, averaged over a 6 month time period. This is in contradiction to the more detailed analysis undertaken here, which clearly shows increased sediment production. However, the anomaly may be explained by their adoption of a statistical modeling approach to calculate sediment production.

\section{Conclusions}

The data presented here demonstrates that at least in some areas sediment production after a seismic event increases through time. In this catchment, it appears that this is the result of increased landslide activity associated with typhoons. Interestingly, similar increases in sediment production were also noted by Keefer (1984) in New Zealand, which has a similar environment to Taiwan.

This study has only considered suspended sediment and bedload and dissolved load are not measured. It is likely that both of these components are substantial, though in a typhoon-affected river they are difficult to measure. It is clear that after the earthquake, the increase in sediment mobilization resulting from the earthquake has elevated the channel bed of the entire Tachia river system downstream from Pai-Lu Bridge station by $30 \mathrm{~m}$ or more in places. The impact of this extensive landsliding is felt many kilometers downstream, and as a result of the elevated stream bed, large floods now have a smaller channel cross-section through which to flow. This has resulted in extensive flooding and infrastructure damage, even though the discharges have not increased.

The impacts of earthquakes and typhoons are difficult to predict both spatially and temporally, and their effects should be considered in the management of catchments in dynamic environments such as Taiwan. These considerations should be included in the design of communication and water supply infrastructures.

\section{References}

Central Weather Bureau, 2004, Historical typhoon data: http:// www.cwb.gov.tw/V4/typhoon/history/typhoon-history.htm (accessed April 2004).

Dadson, S.J., Hovius, N., Chen, H., Dade, W.B., Hsieh, M.L., Willett, S.D., Hu, J.H., Horng, M.J., Chen, M.J., Stark, C.P., Lague, D., Lin, J.C., 2003. Links between erosion, runoff variability, and seismicity in the Taiwan orogen. Nature 426, 648-651.

Dadson, S.J., Hovius, H., Chen, H., Dade, W.B., Lin, J.C., Hsu, M.L., Lin, C.W., Horng, M.J., Chen, T.J., Milliman, J., 2004. Earthquaketriggered increase in sediment delivery from an active mountain belt. Geology 32 (8), 733-736.

Keefer, D.K., 1984. Landslides caused by earthquakes. Bulletin of the Geological Society of America 95, 406-421.

Konishi, K., Omura, A., Kimura, T., 1968. ${ }^{234} \mathrm{U}-{ }^{230}$ Th dating of some late Quaternary coralline limestones from southern Taiwan (Formosa). Geology and Palaeontology of Southeast Asia 5, 211-224.

Murphy, W., Petley, D.N., Bommer, J., Mankelow, J.W., 2002. Geotechnical and seismological uncertainty in the assessment of slope stability during earthquakes. Quarterly Journal of Engineering Geology and Hydrogeology 35, 71-78.

Pearce, A.J., Watson, A., 1986. Effects of earthquake induced landslides on sediment budget and transport over a 50-year period. Geology 14, 52-55.

Peng, T.H., Li, Y.H., Wu, F.T., 1977. Tectonic uplift rates of the Taiwan Island since the early Holocene. Memoir of the Geological Society of China 2, 57-69.

Rodriguez, C.E., Bommer, J.J., Chandler, R.J., 1999. Earthquake induced landslides 1980-1997. Soil Dynamics and Earthquake Engineering 18, 235-346.

Sepulveda, S.A., Murphy, W., Petley, D.N., 2004. The role of topographic amplification on the generation of earthquake-induced rock slope failures. In: Lacerda, W.A., Ehrlich, M., Fontoura, S.A., Sayao, S.F. (Eds.), Landslides: Evaluation and Stabilization, vol. 1. Balkema, pp. 311-315.

Soil and Water Bureau, 2002. Report of survey and management of landslides caused by the 921 Chi-Chi earthquake. Soil and Water Resources Bureau, Taipei, Taiwan, 112p.

Soil and Water Bureau, 2002. Report of survey and management of landslide caused by 921 Chi-Chi earthquake, 1/112-112/112. 